in vivo $34: 1883-1892(2020)$

doi:10.21873/invivo.11984

\title{
Salvage Photon or Proton Radiotherapy for Oligo-recurrence in Regional Lymph Nodes After Surgery for Non-small Cell Lung Cancer
}

\author{
MASATOSHI NAKAMURA ${ }^{1}$, KAYOKO OHNISHI ${ }^{1}$, HITOSHI ISHIKAWA ${ }^{1}$, KENSUKE NAKAZAWA $^{2}$, \\ TOSHIHIRO SHIOZAWA ${ }^{2}$, TOSHIYUKI OKUMURA ${ }^{1}$, IKUO SEKINE ${ }^{3}$, \\ YUKIO SATO $^{4}$, NOBUYUKI HIZAWA ${ }^{2}$ and HIDEYUKI SAKURAI ${ }^{1}$ \\ ${ }^{1}$ Department of Radiation Oncology, Faculty of Medicine, University of Tsukuba, Ibaraki, Japan; \\ ${ }^{2}$ Department of Respiratory Medicine, Faculty of Medicine, University of Tsukuba, Ibaraki, Japan; \\ ${ }^{3}$ Department of Medical Oncology, Faculty of Medicine, University of Tsukuba, Ibaraki, Japan; \\ ${ }^{4}$ Department of Thoracic Surgery, Faculty of Medicine, University of Tsukuba, Ibaraki, Japan
}

\begin{abstract}
Background/Aim: To evaluate the outcome of definitive salvage radiotherapy $(R T)$ in non-small cell lung cancer (NSCLC) patients with oligo-recurrence in regional lymph nodes after surgery. Patients and Methods: Between January 2003 and December 2016, 33 patients with NSCLC were reviewed from radiotherapy database at our hospital. All patients received photon or proton salvage $R T$ for metastases in the regional lymph nodes. Results: The median follow-up from salvage RT was 35.2 (range=5.9-89.6) months. Recurrences occurred in 18 (55\%) patients, and the 3-year overall and progression-free survival rates were $63.8 \%$ and $45.1 \%$, respectively. Regional and local control improved patients' survival and these control rates were increased by use of concurrent chemotherapy $(p=0.039)$ and proton $R T(p=0.084)$. No grade 4 acute or late nonhematologic toxicities were observed. Conclusion: Salvage $R T$ is an effective treatment for NSCLC patients with oligorecurrence at regional lymph nodes.
\end{abstract}

Lung cancer is a major disease worldwide affecting various tissue types, with non-small cell lung cancer (NSCLC) accounting for approximately $85 \%$ of all lung cancers (1). The standard treatment for patients with stage I/II NSCLC is

This article is freely accessible online.

Correspondence to: Kayoko Ohnishi, MD, Ph.D., Department of Radiation Oncology, Faculty of Medicine, University of Tsukuba 11-1, Tennodai, Tsukuba, Ibaraki, 305-8575, Japan. Tel: +81 298537100, Fax: +81 298537102, e-mail: ohnishi@pmrc.tsukuba.ac.jp

Key Words: Radiotherapy, lymph node metastasis, oligo-recurrence, non-small cell lung cancer. surgery, which is also indicated for some patients with stage IIIA (2-5). However, locoregional recurrence develops in 10$38 \%$ of NSCLC patients as the first recurrence event after complete resection (6-11). Surgery is a radical treatment for locoregional recurrence, but it is difficult to repeat if adhesions are present after the initial surgery. Some reports showed that radiotherapy (RT) for locoregional recurrence after surgery is useful, and that overall survival (OS) can be prolonged by prescribing a radical, rather than palliative, dose (12-16).

The concept of oligo-recurrence was proposed by Niibe $e t$ $a l$. , and local therapies such as surgery and RT can prolong the survival of patients with oligo-recurrence (17). If recurrent tumor cells are limited to locoregional sites, RT is a potential treatment option for isolated regional lymph node oligo-recurrence after complete resection in patients with NSCLC, but few reports have analyzed the clinical outcomes of RT in patients with this type of recurrence (18-22). Therefore, we focused on RT for oligo-recurrence in regional lymph nodes after surgery in patients with NSCLC, and we present the treatment outcomes obtained at our facility.

\section{Patients and Methods}

Patients. The present study was approved by the institutional review board at the University of Tsukuba Hospital (approval no.: H30166). We retrospectively reviewed patients with NSCLC who received definitive salvage photon $\mathrm{RT}$ or proton beam therapy (PBT) for regional lymph node oligo-recurrence after complete resection between January 2003 and December 2016 at our institution. The selection criteria were as follows: i) lymph node recurrence in the unilateral hilum, mediastinum, and supraclavicular fossa as the initial failure event after surgery, ii) no recurrence/metastasis at sites other than the lymph nodes, and iii) photon RT or $\mathrm{PBT} \geq 60 \mathrm{~Gy} / \mathrm{GyE}$ administered with curative intent. A total of 33 patients met the selection criteria. 
Table I. Patient characteristics.

\begin{tabular}{|c|c|c|c|c|c|}
\hline \multicolumn{2}{|l|}{ Patient characteristics } & \multirow{2}{*}{$\frac{\text { Proton RT }(\mathrm{n}=17)}{68(51-80)}$} & \multirow{2}{*}{$\frac{\text { Photon RT }(\mathrm{n}=16)}{71(64-80)}$} & \multirow{2}{*}{$\frac{\text { All }(n=33)}{68(51-80)}$} & \multirow{2}{*}{$\frac{p \text {-Value }}{0.2}$} \\
\hline Age, years & Median (range) & & & & \\
\hline \multirow[t]{2}{*}{ Gender (n) } & Male & 11 & 11 & 22 & \\
\hline & Female & 6 & 5 & 11 & 0.805 \\
\hline \multirow[t]{3}{*}{ PS (n) } & 0 & 10 & 10 & 20 & \\
\hline & 1 & 6 & 6 & 12 & \\
\hline & 2 & 1 & 0 & 1 & 0.616 \\
\hline \multirow[t]{2}{*}{$\mathrm{IP}(\mathrm{n})$} & Yes & 5 & 2 & 7 & \\
\hline & No & 12 & 14 & 26 & 0.235 \\
\hline \multirow[t]{2}{*}{ Surgery type (n) } & Standard & 14 & 13 & 27 & \\
\hline & Limited resection & 3 & 3 & 6 & 0.935 \\
\hline \multirow[t]{8}{*}{$7^{\text {th }}$ UICC disease stage at surgery (n) } & IA & 3 & 5 & 8 & \\
\hline & IB & 3 & 5 & 8 & \\
\hline & IIA & 0 & 2 & 2 & \\
\hline & IIB & 2 & 1 & 3 & \\
\hline & IIIA & 8 & 4 & 12 & \\
\hline & IIIB & 0 & 0 & 0 & \\
\hline & IV & 1 & 0 & 1 & \\
\hline & Unknown & 1 & 0 & 1 & 0.355 \\
\hline \multirow{3}{*}{ Tumor histology (n) } & $\mathrm{SCC}$ & 2 & 10 & 12 & \\
\hline & $\mathrm{AC}$ & 12 & 3 & 15 & \\
\hline & Other & 3 & 3 & 6 & 0.005 \\
\hline \multirow{2}{*}{ Adjuvant chemotherapy received (n) } & Yes & 8 & 4 & 12 & \\
\hline & No & 9 & 12 & 21 & 0.188 \\
\hline Disease-free survival after surgery, months & Median (range) & $24.7(2.2-61.0)$ & $12.7(6.2-54.1)$ & $14.8(2.2-61.0)$ & 0.15 \\
\hline \multirow[t]{2}{*}{ PET received at recurrence (n) } & Yes & 16 & 14 & 30 & \\
\hline & No & 1 & 2 & 3 & 0.509 \\
\hline \multirow[t]{2}{*}{ Number of recurrences (n) } & Single & 7 & 11 & 18 & \\
\hline & Multiple & 10 & 5 & 15 & 0.112 \\
\hline \multirow[t]{3}{*}{ Lymph node recurrence $(\mathrm{n})$} & $\mathrm{rN} 1$ & 1 & 2 & 3 & \\
\hline & $\mathrm{rN} 2$ & 9 & 11 & 20 & \\
\hline & $\mathrm{rN} 3$ & 7 & 3 & 10 & 0.349 \\
\hline $\mathrm{GTV}, \mathrm{cm}^{3}$ & Median (range) & $5.3(1.5-68.1)$ & $7.1(3.5-26.7)$ & $6.6(1.5-68.1)$ & 0.517 \\
\hline Radiation dose, Gy & Median (range) & $70(66-76)$ & $70(60-70)$ & $70(60-76)$ & 0.824 \\
\hline \multirow[t]{2}{*}{ Irradiation field (n) } & ENI & 16 & 14 & 30 & \\
\hline & IFRT & 1 & 2 & 3 & 0.509 \\
\hline \multirow[t]{2}{*}{ CRT received (n) } & Yes & 7 & 3 & 10 & \\
\hline & No & 10 & 13 & 23 & 0.161 \\
\hline \multirow[t]{4}{*}{ CRT regimen $(\mathrm{n})$} & CDDP/VNR & 2 & 3 & 5 & \\
\hline & CBDCA/TS-1 & 3 & 0 & 3 & \\
\hline & UFT & 1 & 0 & 1 & \\
\hline & TS- 1 & 1 & 0 & 1 & 0.232 \\
\hline
\end{tabular}

RT: Radiotherapy; PS: performance status; IP: interstitial pneumonia; UICC: Union for International Cancer Control; PET: positron emission tomography; SCC: squamous cell carcinoma; AC: adenocarcinoma; ENI: elective nodal irradiation; IFRT: involved field radiation; CRT: concurrent chemoradiation; CDDP: cisplatin; VNR, vinorelbine; CBDCA: carboplatin; TS-1, tegafur, gimeracil, and potassium; UFT: tegafur and uracil.

Radiotherapy. For photon RT treatment planning, computed tomography (CT) images were taken at 3 -mm intervals in the treatment position. If necessary, four-dimensional CT images were obtained using a real-time position management respiratory gating system (Varian Medical Systems, Palo Alto, CA, USA). Threedimensional conformal RT plans were made using the Xio treatment planning system (Elekta, Stockholm, Sweden). Photon RT was delivered via 6 or 10 MV x-ray beams using a linear accelerator. For PBT planning, CT images were taken at 2.5- or 5.0-mm intervals in the treatment position using a respiratory-gated system during the endexpiratory phase. Passive-scattering PBT plans were made using the
VQA version 1.7 or 2.0 (Hitachi, Tokyo, Japan), and 155-250 MeV protons were delivered during the end-expiratory phase.

In general, the clinical target volume 1 (CTV1) encompassed the hilar and mediastinal lymph nodes as prophylactic irradiation for patients with positive hilar and/or mediastinal lymph nodes. If the patient had supraclavicular lymph node recurrence, the CTV1 was extended to include the involved supraclavicular lymph node. The CTV2 encompassed only the clinically positive lymph nodes plus a 3-5 mm margin. Clinically positive lymph nodes were defined as nodes $\geq 10 \mathrm{~mm}$ on $\mathrm{CT}$ or as positron emission tomography (PET)positive lymph nodes. The planning target volume (PTV) comprised 
the CTV plus a 5-10 mm margin. After $40 \mathrm{~Gy} / \mathrm{GyE}$ in 20 fractions was delivered to the PTV1, the total dose to the PTV2 was boosted to $60-70 \mathrm{~Gy} / \mathrm{GyE}$ in $30-35$ fractions. Involved field RT (IFRT), which was used to irradiate clinically positive lymph nodes with 5 $\mathrm{mm}$ margins, was indicated for high-risk patients with comorbidities, such as interstitial pneumonia, at the discretion of the radiation oncologist.

Overall, 16 patients were treated with photon RT and 17 with PBT. The median total dose was 70 (range $=60-70$ ) Gy for photon RT and 70 (range=60-76) GyE for PBT. IFRT was used in three patients: one with interstitial pneumonia and the other two for unknown reasons.

Follow-up procedures and statistical analysis. The patients were followed-up with a physical examination, chest x-ray, and blood test every 2-3 months after RT, and imaging studies such as CT and magnetic resonance imaging were performed every 6-12 months. Local progression within the radiation field was defined as an increase in the size of the irradiated lymph nodes on CT or PET/CT. Adverse events were assessed according to the Common Terminology Criteria for Adverse Effects, version 4.0 (23).

The follow-up interval was defined from the first day of RT to the date of death or the last follow-up. The OS, progression-free survival (PFS), distant metastasis-free survival, local progression-free (LPF), and regional control (RC) rates were calculated from the first day of RT to the date of that event or the last follow-up using the KaplanMeier method, and significant differences between survival curves were assessed using the log-rank test. A $p$-value $<0.05$ was considered statistically significant. The SPSS, version 25 (IBM, Co., Armonk, NY) software was used for the statistical analyses.

\section{Results}

Study population. Patient and tumor characteristics are shown in Table I. The patients comprised 22 men, and the median age was 68 (range $=51-80$ ) years. The pathological stage according to the 7 th version of the UICC TNM classification was I in 14 patients, II in 5, III in 12 , IV in 1 , and unknown in 1 . The histology was squamous cell carcinoma in 12 patients, adenocarcinoma in 15, and other in 6 . Twelve $(36 \%)$ patients received adjuvant chemotherapy after surgery. The median time from surgery to recurrence was 14.8 (range=2.2-61.0) months. Thirty (91\%) patients underwent PET/CT at the time of recurrence. The $\mathrm{rN}$ stage was $\mathrm{rN} 1$ in 3 patients, rN2 in 20, and rN3 in 10. Recurrence developed at single and multiple lymph node stations in 15 and 18 patients, respectively. Concurrent chemotherapy with RT was administered in $10(30 \%)$ patients.

Survival and locoregional control after radiotherapy. At the last follow-up, 14 patients had died: 8 (24\%) from progression of their disease, $5(15 \%)$ from intercurrent disease, and 1 (3\%) from unknown cause. The median follow-up from the first day of RT was 35.2 (range=5 .9-89.6) months for all patients and 42.5 (range=7.8-70.3) months for the surviving patients. Details of the failure patterns are shown in Table II. Recurrences were observed in 18 (55\%)
Table II. Initial recurrence pattern after RT.

\begin{tabular}{llr}
\hline Field & \multicolumn{1}{c}{ Site } & $n$ \\
\hline Inside the radiation field & & \\
Regional LN recurrence & Site irradiated with $>60$ Gy & 4 \\
Outside the radiation field & & \\
Regional LN recurrence & Ipsilateral supraclavicular LN & 3 \\
& Contralateral supraclavicular LN & 1 \\
& Adjacent mediastinal LN & 1 \\
& Contralateral hilar LN & 1 \\
Regional LN recurrence & LN (outside radiation field) & 1 \\
+ DM & and lung & 1 \\
& LN (inside and outside radiation & \\
& field) and kidney & 2 \\
DM & Lung & 2 \\
& Bone and lung & 1 \\
& Bone & 1 \\
& Brain & \\
\hline
\end{tabular}

LN, Lymph nodes; DM, distant metastasis.

of 33 patients: $10(30 \%)$ at regional lymph nodes only, 6 $(18 \%)$ at distant organs only, and $2(61 \%)$ at both. All cases of regional recurrence within the radiation field occurred in the area receiving the $60-70 \mathrm{~Gy} / \mathrm{GyE}$ boost. All six patients who experienced regional recurrence only (i.e., no distant metastasis) outside the radiation field achieved RC after repeat definitive RT, but five (83\%) of them developed distant metastases.

The 3-year OS, PFS, and distant metastasis-free survival rates after RT were $63.8 \%$ [95\% confidence interval $(\mathrm{CI})=46.3-81.2 \%$ ], $45.1 \%(95 \% \mathrm{CI}=27.9-62.1 \%)$, and $53.6 \%$ (95\% CI=36.2-70.9\%), respectively (Figure 1). The 3-year $\mathrm{RC}$ and LPF rates were $63.3 \%(95 \% \mathrm{CI}=45.8-80.7 \%)$ and $79.7 \%$ (95\% CI=65.1-94.3\%), respectively (Figure 2). Both the 3 -year OS (70.3\% vs. 53.9\%, $p=0.116$; Figure 3a) and PFS $(64.6 \%$ vs. $15.4 \%, p<0.001$; Figure $3 b)$ rates were better in patients with $\mathrm{RC}$ than in those with regional recurrence, although the difference in OS did not reach statistical significance. Patients with local control (LC) also had better 3 -year OS and PFS rates compared to patients with local progression $(69.8 \%$ vs. $42.9 \%, p=0.047$ and $53.6 \%$ vs. $14.3 \%, p=0.013$; Figure $3 \mathrm{c}$ and $3 \mathrm{~d})$.

Prognostic factors. Potential prognostic factors associated with PFS, RC, and LPF are shown in Table III. The 3-year PFS rate was significantly better in patients with a performance status (PS) of 0 compared to $\geq 1$ (59.6\% vs. $23.1 \%, p=0.017)$. Use of concurrent chemotherapy with salvage RT significantly improved the RC rate compared with RT alone ( $87.5 \%$ vs. $53.9 \%, p=0.039)$. However, other factors including age, sex, disease stage, and the status of lymph node recurrence were not related to survival outcomes. 


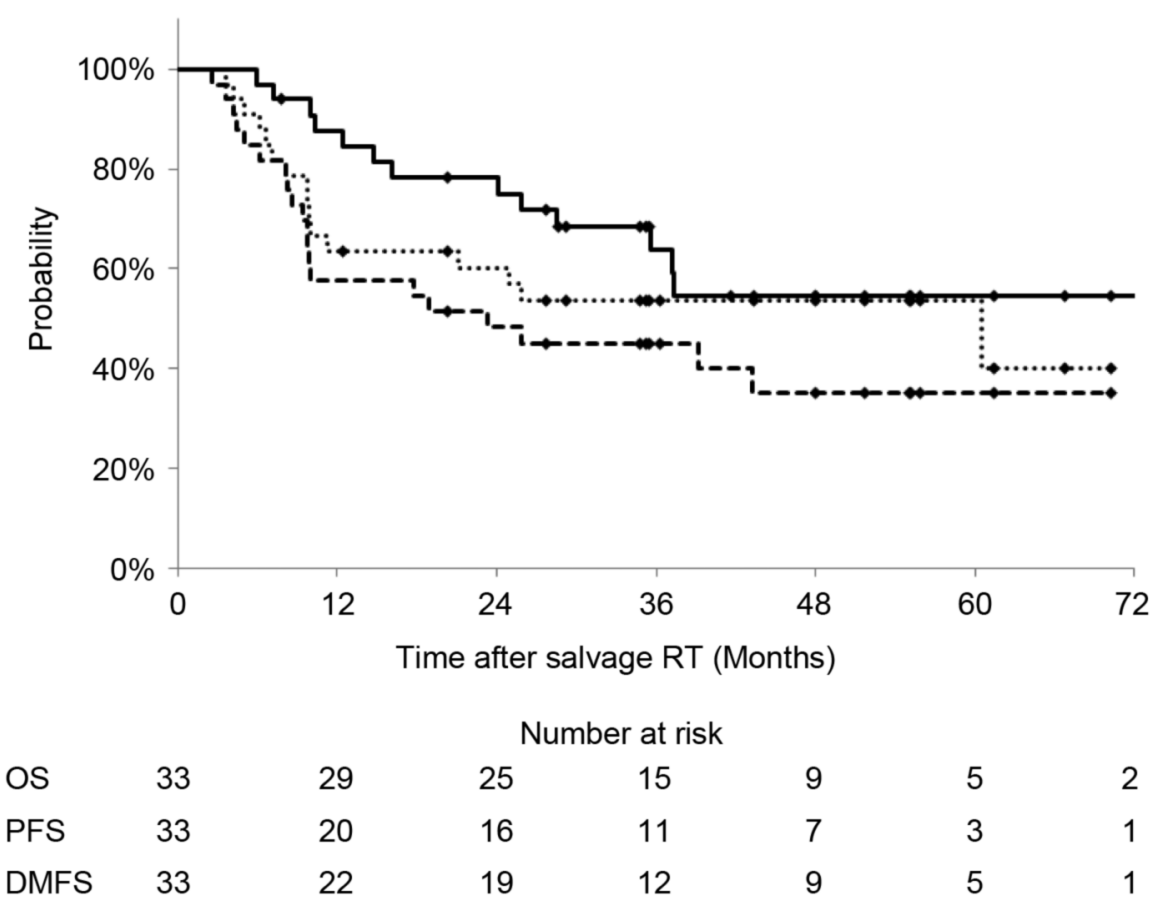

Figure 1. Overall, progression-free, and distant metastasis-free survival curves for the patients in this study. Straight, dashed, and dotted lines indicate overall, progression-free, and distant metastasis-free survival, respectively.

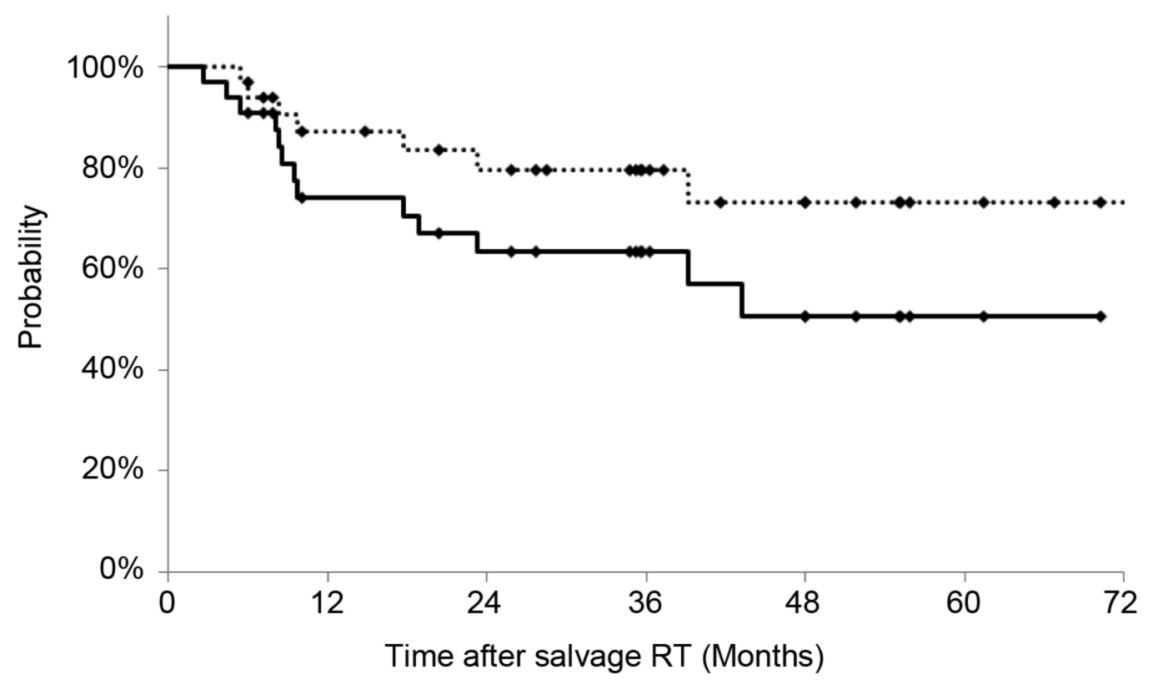

Figure 2. Regional control and local progression-free rates. Straight and dotted lines indicate regional control and local progression-free rates, respectively.

Adverse events. In the present study, grade 2 esophagitis was observed in seven patients (three and four treated with photon RT and PBT, respectively) and grade 3 esophagitis in one patient (photon RT). The patient with grade 3 esophagitis developed grade 3 esophageal stricture as a late morbidity at
7.5 months after salvage RT. Grade 2 pneumonitis occurred in four patients (one and three treated with photon RT and PBT, respectively). Among these patients, one required steroid treatment, but no grade 3 or more severe RT-related toxicities other than esophagitis were observed. 
A

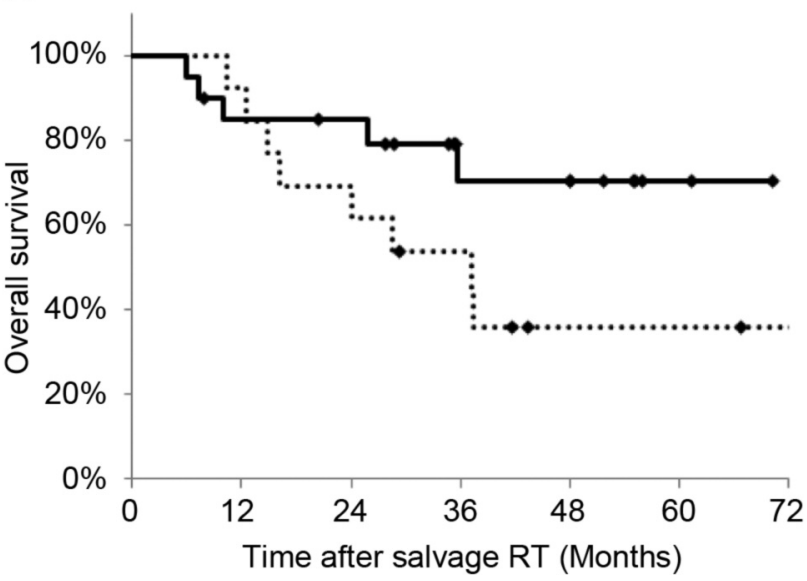

C

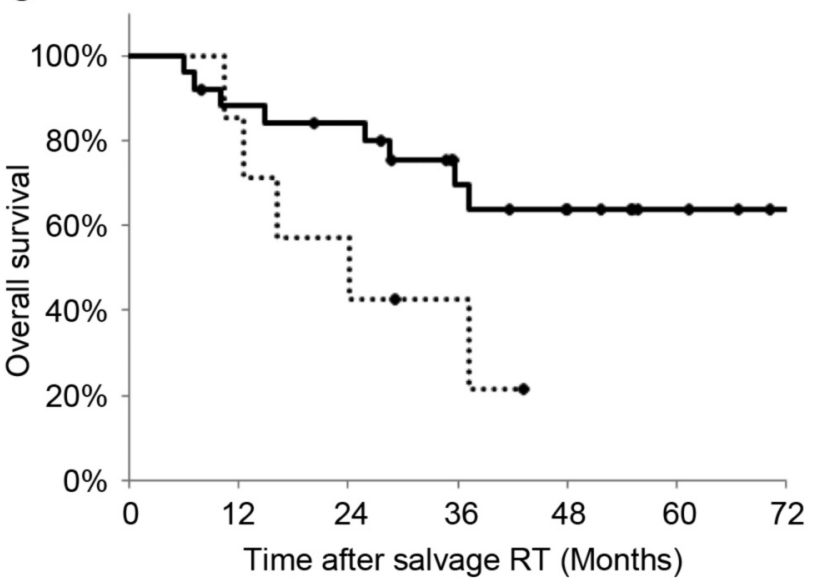

B

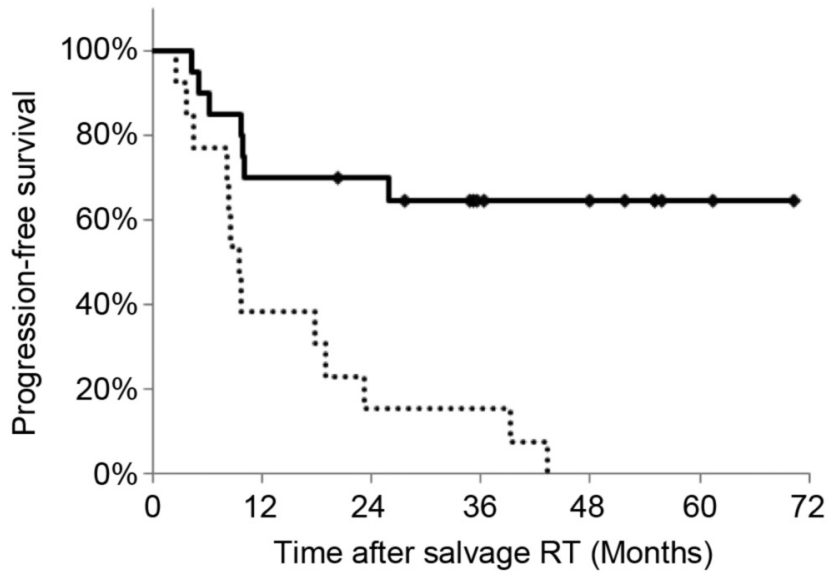

D

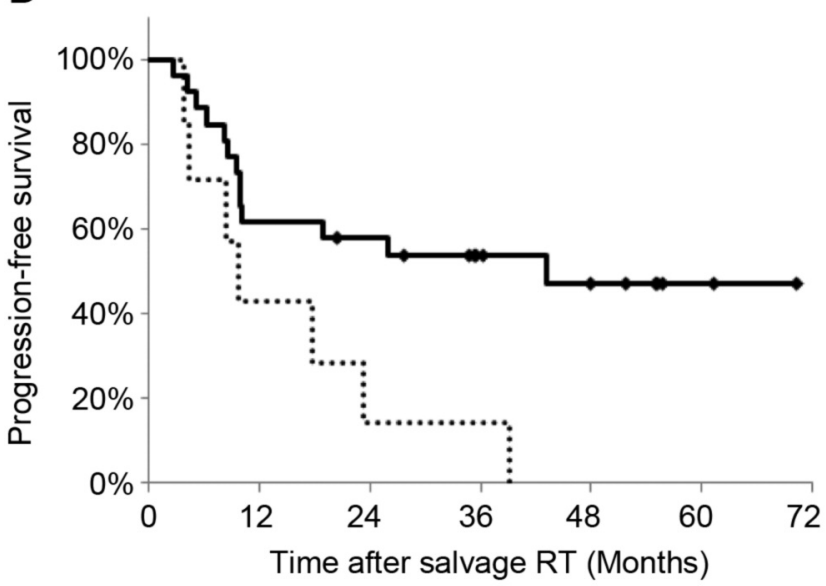

Figure 3. Survival curves according to regional and local control. (a) Overall survival of the patients with regional control (straight line) vs. recurrence (dotted line). The 3-year rates in the control and recurrence groups were 70.3\% and 53.9\%, respectively ( $p=0.116)$. (b) Progressionfree survival of the patients with regional control (straight line) vs. recurrence (dotted line). The 3-year rates in the control and recurrence groups were $64.6 \%$ and $15.4 \%$, respectively $(p<0.001)$. (c) Overall survival of the patients with local control (straight line) vs. recurrence (dotted line). The 3-year rates in the control and recurrence groups were $69.8 \%$ and $42.9 \%$, respectively $(p=0.047)$. (d) Progression-free survival of the patients with local control (straight line) vs. recurrence (dotted line). The 3-year rates in the control and recurrence groups were 53.6\% and $14.3 \%$, respectively $(p=0.013)$.

\section{Discussion}

Oligo-recurrence is defined as one or more distant metastasis/recurrence event (usually one) in one or more organs (usually one), despite control of the primary cancer site, that can be treated with local therapy, with no other distant metastasis/recurrence event present (17). Therefore, patients with oligo-recurrence still have a chance of being cured by aggressive local therapies such as salvage surgery and RT. Especially in cases of oligo-recurrence in regional lymph nodes but not distant organs after surgery, it is possible that the tumor cells do not spread systematically, and thus salvage therapy will be very effective (18). Therefore, we focused on oligo-recurrence of NSCLC in regional lymph nodes and analyzed survival outcomes after salvage RT with curative intent. In the present study, the 3-year OS rate of patients with $\mathrm{RC}$ was better than that of patients with regional lymph node recurrence, but this difference was not significant (70.3\% vs. 53.9\%, $p=0.116$ ). Therefore, we cannot conclude on the efficacy of salvage RT in these patients; however, the main reason for the non-significant result was likely our small sample size $(n=33)$ due to the rarity of this disease. On the other hand, the difference in the 3-year PFS rate between those with $\mathrm{RC}$ than those with regional lymph node recurrence was significant ( $p<0.001$; Figure $3 b)$. Therefore, obtaining RC after salvage but definitive RT for oligorecurrence in regional lymph nodes appears important especially for patients with a good PS. 
Table III. Univariate analysis of prognostic factors for survival and disease control.

\begin{tabular}{|c|c|c|c|c|c|c|c|c|c|}
\hline Factor & $\begin{array}{l}\text { Total } \\
(\mathrm{N}=33)\end{array}$ & $\begin{array}{l}\text { 3-year OS } \\
\text { rate }(\%)\end{array}$ & $p$-Value & $\begin{array}{c}\text { 3-year PFS } \\
\text { rate }(\%)\end{array}$ & $p$-Value & $\begin{array}{l}\text { 3-year RC } \\
\text { rate }(\%)\end{array}$ & $p$-Value & $\begin{array}{l}\text { 3-year LPF } \\
\text { rate }(\%)\end{array}$ & $p$-Value \\
\hline $\begin{array}{l}\text { Age } \\
<68 v s . \geq 68 \text { years }\end{array}$ & 14 vs. 19 & 72.5 vs. 57.4 & 0.346 & 57.1 vs. 36.8 & 0.319 & $69.2 v s .59 .1$ & 0.622 & 83.9 vs. 76.8 & 0.415 \\
\hline $\begin{array}{l}\text { Gender } \\
\text { Male vs. female }\end{array}$ & 22 vs. 11 & $60.8 v s .70 .1$ & 0.242 & 45 vs. 45.5 & 0.897 & 63.3 vs. 63.6 & 0.928 & 79.2 vs. 80.8 & 0.585 \\
\hline $\begin{array}{l}\text { Performance status } \\
0 \text { vs. } 1\end{array}$ & 20 vs. 13 & 70.5 vs. 53.8 & 0.152 & 59.6 vs. 23.1 & 0.017 & 73.7 vs. 44.0 & 0.09 & 89.5 vs. 62.9 & 0.037 \\
\hline $\begin{array}{l}7^{\text {th }} \text { UICC stage at surgery } \\
\text { I vs. II-IV }\end{array}$ & 14 vs. 18 & $41.7 v s .79 .4$ & 0.072 & 35.7 vs. 55.6 & 0.469 & 60.0 vs. 70.8 & 0.826 & 75.5 vs. 88.1 & 0.633 \\
\hline $\begin{array}{l}\text { Tumor histology } \\
\text { Adenocarcinoma } v s . \text { other }\end{array}$ & 15 vs. 18 & 70.0 vs. 59.0 & 0.214 & 60.0 vs. 33.3 & 0.154 & 79 vs. 49.4 & 0.105 & 92.9 vs. 68.2 & 0.065 \\
\hline $\begin{array}{l}\text { Adjuvant chemotherapy } \\
\text { Yes } v s . \text { no }\end{array}$ & 12 vs. 21 & 87.5 vs. 52.3 & 0.044 & 58.3 vs. 38.1 & 0.326 & $81.8 v s .52 .6$ & 0.153 & 100 vs. 67.3 & 0.131 \\
\hline $\begin{array}{l}\text { Disease-free interval } \\
\text { after surgery } \\
\quad<1 \text { vs. } \geq 1 \text { year }\end{array}$ & 12 vs. 21 & $54.5 v s .68 .6$ & 0.842 & 47.1 vs. 41.7 & 0.835 & 64.2 vs. 63.4 & 0.684 & 90.9 vs. 73.9 & 0.194 \\
\hline $\begin{array}{l}\text { Number of LN stations } \\
\text { with recurrence } \\
\text { Single vs. multiple }\end{array}$ & 18 vs. 15 & $70.6 v s .54 .2$ & 0.677 & $60.6 v s .26 .7$ & 0.086 & $71.8 v s .50 .9$ & 0.634 & 83 vs. 75.4 & 0.901 \\
\hline $\begin{array}{l}\text { Stage of lymph node } \\
\text { recurrence } \\
\text { rN1/2 vs. rN3 }\end{array}$ & 23 vs. 10 & $62.5 v s .64 .0$ & 0.533 & 43.0 vs. 50.0 & 0.666 & $58.0 \mathrm{vs} .75 .0$ & 0.398 & $76.6 v s .87 .5$ & 0.822 \\
\hline $\begin{array}{l}\text { Concurrent chemotherapy } \\
\text { Yes } v s . \text { no }\end{array}$ & 10 vs. 23 & $65.6 v s .64 .9$ & 0.592 & 50 vs. 43.5 & 0.557 & 87.5 vs. 53.9 & 0.039 & 87.5 vs. 76.5 & 0.354 \\
\hline $\begin{array}{l}\text { Type of radiation } \\
\text { Photon } v s \text {. proton }\end{array}$ & 16 vs. 17 & $55.6 v s .75 .6$ & 0.256 & 37.5 vs. 52.3 & 0.372 & 50.0 vs. 76.6 & 0.084 & $68.8 v s .90 .9$ & 0.054 \\
\hline
\end{tabular}

UICC: Union for International Cancer Control; LN: lymph node; OS: overall survival; PFS: progression-free survival; RC: regional control; LPF: local progression-free.

Only few reports have analyzed the outcomes of definitive RT for postoperative lymph node oligo-recurrence in patients with NSCLC. Okami et al. retrospectively reviewed 50 patients treated with RT for thoracic lymph node recurrence after complete resection of the primary NSCLC and reported 3-year OS, PFS, and LC rates of 52.7\%, 28.2\%, and $65.9 \%$, respectively, compared with a 3 -year OS rate of $5.9 \%$ in patients who did not receive RT (24). Imai et al. evaluated 33 patients who received RT for postoperative lymph node recurrence in the ipsilateral mediastinum and reported 2-year OS and PFS rates of $78.5 \%$ and $36.0 \%$, respectively (25). Seol et al. reported 2-year PFS and LC rates of $50.9 \%$ and $75.8 \%$, respectively, among 31 patients treated with RT for regional lymph node recurrence after surgery (26). In a recent report analyzing the outcomes of three-dimensional conformal RT $(92.9 \%)$ and intensity-modulated RT $(7.1 \%)$ using IFRT in 127 patients with postoperative mediastinal nodal relapse, the 2- and 5-year OS rates were $72.9 \%$ and $43.9 \%$, and the 2- and 5- year LPF rates were $82.4 \%$ and $73.8 \%$, respectively (27).

The outcomes of definitive RT for patients with regional recurrence of NSCLC after surgery reported by previous studies are summarized in Table IV. In the present study, the 3-year OS, PFS, and LC rates were $63.8 \%, 45.1 \%$, and $79.7 \%$, respectively. These rates are comparable to those reported by Lee et al. (27) and slightly better than those reported by the other three abovementioned studies (24-26), despite the fact that only $30 \%$ of the patients in the present study were treated with concurrent chemotherapy. Consequently, definitive RT after surgery might be a potentially curative treatment option for NSCLC patients with limited regional lymph node recurrence. Large-scale prospective studies are needed to determine the indications and appropriate methods for salvage RT treatment of oligorecurrence from NSCLC.

Regarding the RT method, the optimal CTV and dose fractionation for regional oligo-recurrence after surgery for NSCLC patients have not been established. Although the radiation fields and doses were not consistent among the abovementioned studies, our treatment strategy was to use elective nodal irradiation (ENI) and provide a high radiation dose (median: 70 Gy in 35 fractions) to the metastasized lymph nodes. The main reason why we used ENI was to eradicate microscopic metastases surrounding visible tumors based on studies showing that most recurrences were observed at multiple sites after surgery for $\operatorname{NSCLC}(28,29)$. 
A

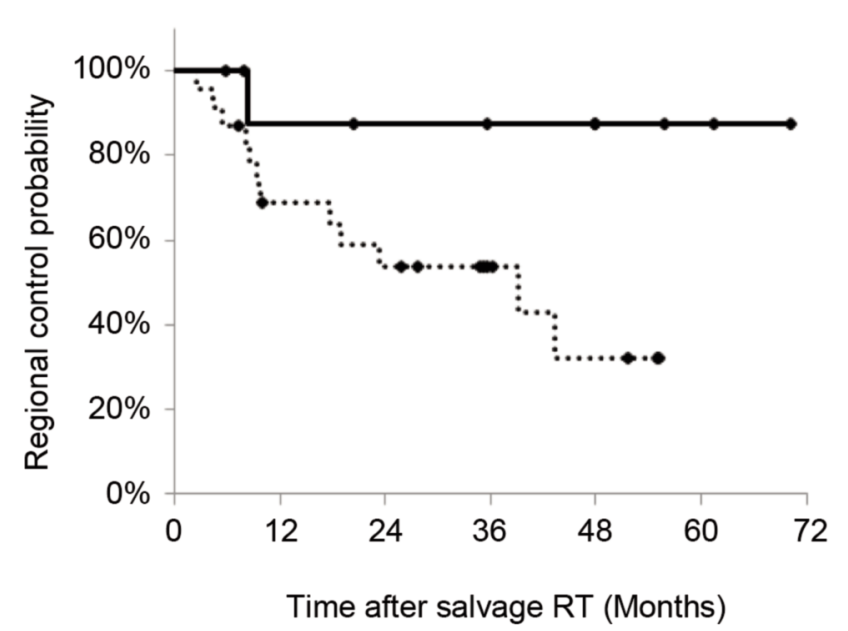

B

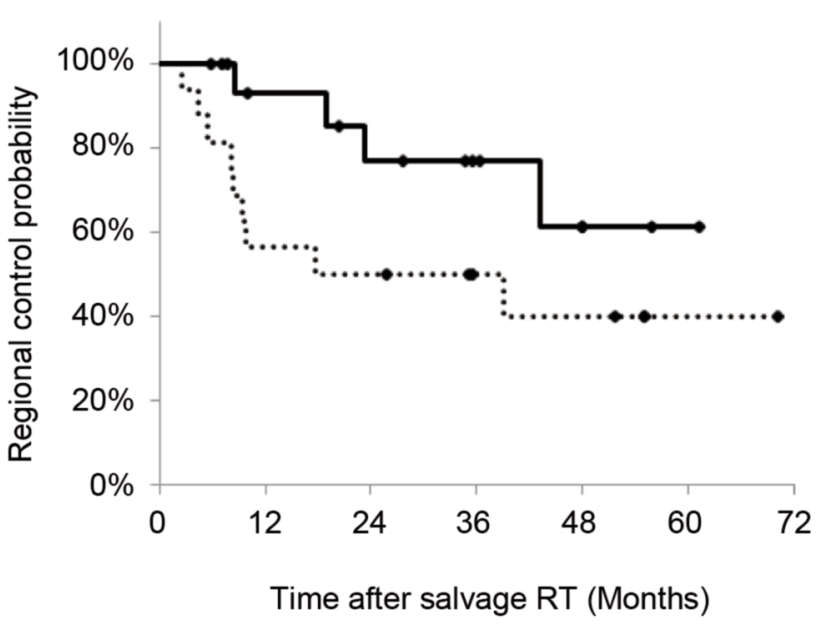

Figure 4. Regional control according to treatment method. (a) Chemoradiotherapy (straight line) vs. radiotherapy alone (dotted line). (b) Proton beam therapy (straight line) vs. photon beam radiotherapy (dotted line).

Table IV. Comparison of radiotherapy outcomes of patients with non-small cell lung cancer developing lymph node recurrence after surgery.

\begin{tabular}{|c|c|c|c|c|c|c|c|c|c|c|c|}
\hline Author & $\mathrm{N}$ & $\begin{array}{l}\text { Postoperative } \\
\text { recurrence } \\
\text { only }\end{array}$ & $\begin{array}{l}\text { Median } \\
\text { age }\end{array}$ & $\begin{array}{c}\text { Treatment } \\
\text { period }\end{array}$ & $\begin{array}{l}\text { Median dose } \\
\text { (prescription } \\
\text { method) }\end{array}$ & $\begin{array}{c}\text { RT } \\
\text { technique }\end{array}$ & $\begin{array}{l}\text { Patients } \\
\text { with AC }\end{array}$ & CRT & $\begin{array}{l}\text { LC rate } \\
\text { (years) }\end{array}$ & $\begin{array}{l}\text { OS rate } \\
\text { (years) }\end{array}$ & $\begin{array}{l}\text { PFS rate } \\
\text { (years) }\end{array}$ \\
\hline $\begin{array}{l}\text { Okami et al. } \\
(2013)\end{array}$ & 50 & Yes & 68 & 1997-2009 & $\begin{array}{l}\text { 60-66 Gy/30-33 fr } \\
\text { (isocenter) }\end{array}$ & 3D-CRT & $42.0 \%$ & $12.0 \%$ & $65.9 \%(3)$ & $52.7 \%(3)$ & $28.2 \%(3)$ \\
\hline $\begin{array}{l}\text { Imai et al. } \\
(2016)\end{array}$ & 33 & Yes & 65 & $2002-2009$ & $\begin{array}{l}60 \mathrm{~Gy} / 30 \mathrm{fr} \\
\text { (isocenter) }\end{array}$ & 3D-CRT & $69.6 \%$ & $39.3 \%$ & N/A & $78.5 \%(2)$ & $36 \%$ (2) \\
\hline $\begin{array}{l}\text { Seol et al. } \\
(2017)\end{array}$ & 31 & Yes & 66 & 2008-2013 & $66 \mathrm{~Gy} / 33 \mathrm{fr}$ & 3D-CRT & $48.4 \%$ & $22.6 \%$ & $75.8 \%(2)$ & $58.4 \%(2)$ & $50.9 \%(2)$ \\
\hline $\begin{array}{l}\text { Lee } \text { et al. } \\
(2018)\end{array}$ & 127 & Yes & 63 & 2004-2016 & $66 \mathrm{~Gy} / 33 \mathrm{fr}$ & $\begin{array}{l}\text { 3D-CRT } \\
\text { IMRT }\end{array}$ & $56.7 \%$ & $94.5 \%$ & $73.8 \%(5)$ & $43.9 \%(5)$ & $22.3 \%(5)$ \\
\hline This study & 33 & Yes & 68 & 2003-2016 & $\begin{array}{l}70 \mathrm{~Gy} / 35 \mathrm{fr} \\
\text { (isocenter) }\end{array}$ & $\begin{array}{l}\text { 3D-CRT } \\
\text { PBT }\end{array}$ & $45.4 \%$ & $30.3 \%$ & $79.7 \%(3)$ & $63.8 \%$ (3) & $45.1 \%(3)$ \\
\hline
\end{tabular}

RT, Radiotherapy; AC, adenocarcinoma; CRT, chemoradiotherapy; LC, local control; OS, overall survival; PFS, progression-free survival; 3D-CRT, three-dimensional conformal radiotherapy; IMRT, intensity modulated radiotherapy; PBT, proton beam therapy.

In addition, high dose in most patients were usually given safely, because the irradiated volumes of the lung at the present setting, especially treated with PBT, were much smaller than those in concurrent chemoradiotherapy for stage III NSCLC as initial therapy. As a result, no grade 3 or more severe RT-related toxicities other than esophagitis were observed, and a good 3-year LC rate $(79.7 \%)$ was achieved. In addition, there were no cases of marginal recurrence, although six patients developed regional recurrence outside of the radiation field; the most common site of recurrence was the supraclavicular fossa. Therefore, it seems that our dose fractionation schedule is effective and well tolerated irrespective of the use of ENI. Further evaluation is needed to determine whether the supraclavicular fossa should be included in the prophylactic area or not. Horne et al. treated patients with lesions involving the hilum or mediastinum from primary or oligo-recurrent NSCLC with stereotactic body RT and reported 2-year RC and LC rates of $64.3 \%$ and $87.7 \%$, respectively (30). In addition, the 3-year PFS rate was $22.5 \%$, and the rates of severe acute and late toxicities were $7.5 \%$ and $2.5 \%$, respectively. Although the cumulative rates of LC, RC, and PFS in that study were similar to our 
rates, more severe adverse events were observed with stereotactic body RT; the efficacy of regional RT on disease control was not reported.

In our study, the 3-year RC and LPF rates tended to be better in the PBT than photon RT group, although these differences were not significant $(50.0 \%$ vs. $76.6 \%, p=0.084$ and $68.8 \%$ vs. $90.9 \%, p=0.054$, respectively). One potential reason for this might be better target coverage by protons than x-ray beams (31), because the build-up and build-down of photons affect the dose reduction at the edge of target volumes located mostly in the hilum and mediastinum adjacent to air. However, in our study, there were differences in the patient background characteristics, such as tumor histology, between the PBT and photon RT groups, and multivariate analyses from large prospective studies are needed.

Various prognostic factors for postoperative recurrence of NSCLC have been reported, including PS, sex, initial stage, time from surgery to the initial relapse, response to the initial treatment for recurrence, recurrence site, number of recurrence events, tissue type and degree of differentiation, and presence of recurrence-related symptoms $(9,11,13-15$, 32). In reports of patients with recurrence limited to the lymph nodes, the absence of symptoms and involvement of a single lymph node station were associated with OS, and the size of the involved lymph node was associated with PFS $(24,26)$. In the present study, PS was the only significant factor associated with the 3-year PFS rate. The use of concurrent chemotherapy was associated with RC, but not OS or PFS. Although the advantage of using concurrent chemotherapy with RT has not been established, some studies reported that concurrent chemotherapy tended to improve OS and PFS rates in NSCLC patients with postoperative oligo-recurrence in the mediastinal lymph nodes $(22,25,33,34)$. Imai et al. reported that concurrent chemoradiotherapy resulted in a significantly longer PFS compared with RT alone (median survival: 19.0 vs. 12.5 months) (25). Therefore, concurrent chemoradiotherapy may be an option for patients with good PS to improve outcome.

The major limitations of this study are its retrospective nature, small number of patients, heterogeneous treatment characteristics, and lack of a standardized follow-up schedule. In addition, RT details, such as the prophylactic irradiated area according to the primary tumor location, were not fully evaluated. However, we could not perform a prospective study comparing patients who received RT with those who did not because the OS of latter patients is too short (24). Moreover, collecting sufficient data for analysis in a prospective study might be too difficult due to too few cases. Therefore, we consider that the limitations of this study were unavoidable.

In conclusion, 33 patients with postoperative oligorecurrence of NSCLC in regional lymph nodes who were treated with RT or PBT showed favorable survival and control rates and no severe adverse events. The RC rate might be improved using RT or PBT with concurrent chemotherapy. RT or PBT for NSCLC oligo-recurrence in regional lymph nodes after surgery is considered an effective treatment option, and further prospective studies are expected.

\section{Conflicts of Interest}

The Authors have no conflicts of interest to disclose regarding this manuscript.

\section{Authors' Contributions}

Study concept and design: MN, KO. Data Collection: KN, TS, TO, SY. Data analysis: MN, KO, HI. Drafting of the manuscript: MN, HI. Critical revision of the manuscript: IS. Study supervision: HS.

\section{Acknowledgements}

The present work was presented at the $61^{\text {st }}$ annual meeting of American Society for Radiation Oncology held in September, 2019. The Authors are grateful to JAM Post (www.jamp.com).

\section{References}

1 Siegel RL, Miller KD and Jemal A: Cancer statistics, 2019. CA Cancer J Clin 69(1): 7-34, 2019. PMID: 31810952. DOI: $10.3322 /$ caac. 21551

2 Sawabata N, Miyaoka E, Asamura H, Nakanishi Y, Eguchi K, Mori M, Nomori H, Fujii Y, Okumura M and Yokoi K: Japanese lung cancer registry study of 11,663 surgical cases in 2004: Demographic and prognosis changes over decade. J Thorac Oncol 6(7): 1229-1235, 2011. PMID: 21610521. DOI: 10.1097/JTO.0b013e318219aae2

3 Spaggiari L, Tessitore A, Casiraghi M, Guarize J, Solli P, Borri A, Gasparri R, Petrella F, Maisonneuve P and Galetta D: Survival after extended resection for mediastinal advanced lung cancer: Lessons learned on 167 consecutive cases. Ann Thorac Surg 95(5): 1717-1725, 2013. PMID: 23566644. DOI: 10.1016/ j.athoracsur.2013.01.088

4 Watanabe S, Asamura H, Miyaoka E, Okumura M, Yoshino I, Fujii Y, Nakanishi Y, Eguchi K, Mori M, Sawabata N and Yokoi $\mathrm{K}$ : Results of 44 surgical cases in the japanese lung cancer registry study: Should mediastinal fat tissue invasion really be included in the $\mathrm{t} 4$ category? J Thorac Oncol 8(6): 759-765, 2013. PMID: 23608818. DOI: 10.1097/JTO.0b013e318290912d

5 Yoshino I, Yoshida S, Miyaoka E, Asamura H, Nomori H, Fujii Y, Nakanishi Y, Eguchi K, Mori M, Sawabata N, Okumura M and Yokoi K: Surgical outcome of stage iiia- cn2/pn2 non-smallcell lung cancer patients in japanese lung cancer registry study in 2004. J Thorac Oncol 7(5): 850-855, 2012. PMID: 22481238. DOI: $10.1097 / J T O .0 b 013 e 31824 c 945 b$

6 Billiet C, De Ruysscher D, Peeters S, Decaluwe H, Vansteenkiste J, Dooms C, Deroose CM, De Leyn P, Hendrikx M, Bulens P, Le Pechoux C and Mebis J: Patterns of locoregional relapses in patients with contemporarily staged stage iii-n 2 nsclc treated with induction 
chemotherapy and resection: Implications for postoperative radiotherapy target volumes. J Thorac Oncol 11(9): 1538-1549, 2016. PMID: 27374454. DOI: 10.1016/j.jtho.2016.05.037

7 Endo C, Sakurada A, Notsuda H, Noda M, Hoshikawa Y, Okada $\mathrm{Y}$ and Kondo T: Results of long-term follow-up of patients with completely resected non-small cell lung cancer. Ann Thorac Surg 93(4): 1061-1068, 2012. PMID: 22386090. DOI: 10.1016/j. athoracsur.2012.01.004

8 Fedor D, Johnson WR and Singhal S: Local recurrence following lung cancer surgery: Incidence, risk factors, and outcomes. Surg Oncol 22(3): 156-161, 2013. PMID: 23702313. DOI: 10.1016/j.suronc.2013.04.002

9 Ichinose Y, Yano T, Yokoyama H, Inoue T, Asoh H, Tayama K and Takanashi N: Postrecurrent survival of patients with nonsmall-cell lung cancer undergoing a complete resection. J Thorac Cardiovasc Surg 108(1): 158-161, 1994. PMID: 8028360. DOI: 10.1016/S0022-5223(94)70233-0

10 Thomas P and Rubinstein L: Cancer recurrence after resection: T1 n0 non-small cell lung cancer. Lung cancer study group. Ann Thorac Surg 49(2): 242-246, 1990. PMID: 2154958. DOI: 10.1016/0003-4975(90)90145-v

11 Yano T, Hara N, Ichinose Y, Asoh H, Yokoyama H, Ohta M and Hata K: Local recurrence after complete resection for non-smallcell carcinoma of the lung. Significance of local control by radiation treatment. J Thorac Cardiovasc Surg 107(1): 8-12, 1994. PMID: 8283923. DOI: 10.1016/S0022-5223(94)70445-7

12 Jeremic B, Shibamoto Y, Milicic B, Milisavljevic S, Nikolic N, Dagovic A, Aleksandrovic J and Radosavljevic-Asic G: External beam radiation therapy alone for loco-regional recurrence of non-small-cell lung cancer after complete resection. Lung Cancer 23(2): 135-142, 1999. PMID: 10217617. DOI: $10.1016 / \mathrm{s} 0169-5002(99) 00007-0$

13 Nakagawa T, Okumura N, Ohata K, Igai H, Matsuoka T and Kameyama K: Postrecurrence survival in patients with stage $\mathrm{i}$ non-small cell lung cancer. Eur J Cardiothorac Surg 34(3): 499504, 2008. PMID: 18579404. DOI: 10.1016/j.ejcts.2008.05.016

14 Shimada Y, Saji H, Yoshida K, Kakihana M, Honda H, Nomura M, Usuda J, Kajiwara N, Ohira T and Ikeda N: Prognostic factors and the significance of treatment after recurrence in completely resected stage i non-small cell lung cancer. Chest 143(6): 1626-1634, 2013. PMID: 23348916. DOI: $10.1378 /$ chest.12-1717

15 Sonobe M, Yamada T, Sato M, Menju T, Aoyama A, Sato T, Chen F, Omasa M, Bando $\mathrm{T}$ and Date H: Identification of subsets of patients with favorable prognosis after recurrence in completely resected non-small cell lung cancer. Ann Surg Oncol 21(8): 2546-2554, 2014. PMID: 24633668. DOI: 10.1245/ s10434-014-3630-9

16 Yano T, Okamoto T, Fukuyama S and Maehara Y: Therapeutic strategy for postoperative recurrence in patients with non-small cell lung cancer. World J Clin Oncol 5(5): 1048-1054, 2014. PMID: 25493240. DOI: 10.5306/wjco.v5.i5.1048

17 Niibe Y and Hayakawa K: Oligometastases and oligo-recurrence: The new era of cancer therapy. Jpn J Clin Oncol 40(2): 107-111, 2010. PMID: 20047860. DOI: 10.1093/jjco/hyp167

18 Hishida T, Yoshida J, Aokage K, Nagai K and Tsuboi M: Postoperative oligo-recurrence of non-small-cell lung cancer: Clinical features and survival dagger. Eur J Cardiothorac Surg 49(3): 847-853, 2016. PMID 26201958. DOI: 10.1093/ ejcts/ezv249
19 Kagami Y, Nishio M, Narimatsu N, Mjoujin M, Sakurai T, Hareyama $M$ and Saito A: Radiotherapy for locoregional recurrent tumors after resection of non-small cell lung cancer. Lung Cancer 20(1): 31-35, 1998. PMID: 9699185. DOI: 10.1016/s0169-5002(98)00008-7

20 Kim E, Song C, Kim MY and Kim JS: Long-term outcomes after salvage radiotherapy for postoperative locoregionally recurrent non-small-cell lung cancer. Radiat Oncol J 35(1): 5564, 2017. PMID: 28183160. DOI: 10.3857/roj.2016.01928

21 Ma L, Qiu B, Zhang J, Li QW, Wang B, Zhang XH, Qiang MY, Chen ZL, Guo SP and Liu H: Survival and prognostic factors of non-small cell lung cancer patients with postoperative locoregional recurrence treated with radical radiotherapy. Chin J Cancer 36(1): 93, 2017. PMID: 29228994. DOI: 10.1186/ s40880-017-0261-0

22 Nakamichi S, Horinouchi H, Asao T, Goto Y, Kanda S, Fujiwara Y, Nokihara H, Yamamoto N, Ito Y, Watanabe SI and Ohe Y: Comparison of radiotherapy and chemoradiotherapy for locoregional recurrence of non-small-cell lung cancer developing after surgery. Clin Lung Cancer 18(6): e441-e448, 2017. PMID: 28583380. DOI: 10.1016/j.cllc.2017.05.005

23 NCI: Common terminology criteria for adverse events (ctcae) v4.0. US Department of Health and Human Services, National Cancer Imstitute, 2010. Available at: https://ctep.cancer.gov/ protocolDevelopment/electronic_applications/ctc.htm [Last accessed on 3rd March 2020]

24 Okami J, Nishiyama K, Fujiwara A, Konishi K, Kanou T, Tokunaga T, Teshima T and Higashiyama M: Radiotherapy for postoperative thoracic lymph node recurrence of non-small-cell lung cancer provides better outcomes if the disease is asymptomatic and a single-station involvement. J Thorac Oncol 8(11): 1417-1424, 2013. PMID: 24077458. DOI: 10.1097/ JTO.0b013e3182a5097b

25 Imai H, Murakami H, Yoshino R, Mori K, Sumita K, Ono A, Akamatsu H, Taira T, Kenmotsu H, Harada H, Naito T, Kaira K, Tomizawa Y, Ohde Y, Matsuura M, Endo M, Saito R, Nakajima $\mathrm{T}$ and Takahashi $\mathrm{T}$ : Comparison of the efficacy of radiotherapy between postoperative mediastinal lymph node recurrence and stage iii disease in non-small cell lung cancer patients. J buon 21(2): 333-340, 2016. PMID: 27273942.

26 Seol KH, Lee JE, Cho JY, Lee DH, Seok Y and Kang MK: Salvage radiotherapy for regional lymph node oligo-recurrence after radical surgery of non-small cell lung cancer. Thorac Cancer 8(6): 620-629, 2017. PMID: 28906073. DOI: 10.1111/ 1759-7714.12497

27 Lee KH, Ahn YC, Pyo H, Noh JM, Park SG, Kim TG, Lee E, Nam H, Lee H, Sun JM, Ahn JS, Ahn MJ and Park K: Salvage concurrent chemo-radiation therapy for loco-regional recurrence following curative surgery of non-small cell lung cancer. Cancer Res Treat 51(2): 769-776, 2019. PMID: 30205417. DOI: $10.4143 /$ crt.2018.366

28 Kelsey CR, Light KL and Marks LB: Patterns of failure after resection of non-small-cell lung cancer: Implications for postoperative radiation therapy volumes. Int J Rdiat Oncol Biol Phys 65(4): 1097-1105, 2006. PMID: 16682136. DOI: 10.1016/ j.ijrobp.2006.02.007

29 Feng W, Fu XL, Cai XW, Yang HJ, Wu KL, Fan M, Xiang JQ, Zhang YW and Chen HQ: Patterns of local-regional failure in completely resected stage iiia (n2) non-small cell lung cancer cases: implications for postoperative radiation therapy clinical 
target volume design. Int J Rdiat Oncol Biol Phys 88(5): 11001107, 2014. PMID: 24529715. DOI: 10.1016/j.ijrobp.2013.12.048

30 Horne ZD, Richman AH, Dohopolski MJ, Clump DA, Burton SA and Heron DE: Stereotactic body radiation therapy for isolated hilar and mediastinal non-small cell lung cancers. Lung Cancer 115: 1-4, 2018. PMID: 29290248. DOI: 10.1016/j.lungcan. 2017.10.014

31 Mondlane G, Ureba A, Gubanski M, Lind PA and Siegbahn A: Estimation of risk of normal-tissue toxicity following gastric cancer radiotherapy with photon- or scanned proton-beams. Anticancer Res 38(5): 2619-2625, 2018. PMID: 29715081. DOI: 10.21873/anticanres. 12503

32 Song IH, Yeom SW, Heo S, Choi WS, Yang HC, Jheon S, Kim $\mathrm{K}$ and Cho S: Prognostic factors for post-recurrence survival in patients with completely resected stage i non-small-cell lung cancer. Eur J Cardiothorac Surg 45(2): 262-267, 2014. PMID: 23811122. DOI: 10.1093/ejcts/ezt333
33 Bar J, Ng D, Moretto P, Goss GD, Sun A, Macrae R, Laurie SA, Leighl $\mathrm{N}$ and Nicholas G: Chemoradiotherapy for locoregional recurrence of non-small-cell lung cancer after surgical resection: A retrospective analysis. Clin Lung Cancer 14(2): 200-204, 2013. PMID: 22868221. DOI: 10.1016/j.cllc.2012.05.008

34 Hisakane K, Yoh K, Nakamura N, Udagawa H, Kirita K, Umemura S, Matsumoto S, Niho S, Akimoto T, Tsuboi M and Goto K: Salvage chemoradiotherapy with cisplatin and vinorelbine for postoperative locoregional recurrence of nonsmall cell lung cancer. Medicine (Baltimore) 96(47): e8635, 2017. PMID: 29381935. DOI: 10.1097/md.0000000000008635

Received March 8, 2020

Revised April 3, 2020

Accepted April 6, 2020 